\title{
PROPUESTA DE UNA UNIDAD DIDÁCTICA PARA ANALIZAR LOS DESASTRES NATURALES EN SÉTIMO \\ AÑO \\ Lic. Alvaro Masis. Introducción
}

Uno de los objetivos de la educación superior universitaria, es promover la creatividad y la originalidad bajo propuestas viables que lleguen a solucionar parcialmente los problemas de la educación; el siguiente artículo pretende rescatar ese objetivo con la elaboración de un planeamiento didáctico que involucre una unidad en uno de los temas contenidos en los programas de Estudios Sociales, para sétimo año del III ciclo de la educación general básica.

La elaboración del planeamiento didáctico centra su atención en el paradigma cognitivo, por consiguiente, el currículo es cognitivo, "centrado en la persona" (González, SF, p.9), en otras palabras, bajo el tema denominado "desastres naturales", se busca que el estudiante no sólo comprenda los fenómenos naturales, sino que los interiorice e incorpore a su esquema mental, para lograr sensibilizarlo ante las consecuencias negativas (en el campo humano) que acarrea un desastre natural de esta magnitud.

Para efectos de orden y de forma del artículo éste se organiza en tres apartados centrales

El primero: Todo planeamiento didáctico, debe poseer una fundamentación epistemológica, conceptual y pedagógica que oriente el diseño curricular. Aquí se esboza algunos elementos conceptuales sobre el paradigma cognitivo, sobre el tipo de planeamiento didáctico a rescatar y el tipo de currículo que se quiere aplicar en la propuesta didáctica dentro del área de los Estudios Sociales. 
El segundo: Aquí se desarrolla todo el planeamiento didáctico, bajo un "modelo de plan de unidad" (Arce y Quesada, 1991. p.18), que orienta los EJES PROBLEMA de acuerdo con los contenidos seleccionados del tema "desastres naturales" para el nivel del $7^{\circ}$ año de la educación general básica en su III ciclo.

Con la presentación de dos cuadros, el plan de unidad (quincenal) se desarrolla en los elementos curriculares siguientes:

* Ejes problema: Son puntos medulares que dirigen el tema central "desastres naturales". Planteados bajo preguntas generadoras que promueven la discusión en torno a una temática (contenidos) por parte de los(as) estudiantes.

* Contenidos Programáticos: Se refiere a los conceptos desglosados del programa de sétimo año, en el tema "desastres naturales", bajo síntesis de ideas, es decir, no involucra todos los contenidos.

* Recursos: Implica la utilización intencionada de "materiales" de índole cognitivo (que también pueden ser recursos físicos), donde destaca el Mapa semántico, el cuadro analítico entre otros.

* Procedimientos:Son básicamente las estrategias metodológicas (actividades) a seguir dentro del salón de clases para desarrollar el tema.

* Actitudes y valores: Involucra las diferentes actitudes, motivos y aspiraciones que se desea desarrollar en el estudiante sobre el tema.

* Evaluación: Concentra su atención en tres fases: diagnóstica, procesal y autoformativa bajo una escala valorativa sumativa. 
* Tiempo probable: Parte fundamental de la planeación curricular, e involucra la cantidad de tiempo a desarrollar para cumplir con los ejes problema propuestos. (Esto incluye encabezado central).

Finalmente, en el tercer apartado: Se esbozan una serie de recomendaciones, para desarrollar este planeamiento didáctico en cualquier colegio, sea público o privado, así como las posibles ventajas y limitaciones de su operacionalización.

Aparte de estas tres secciones y como aporte adicional, el artículo finaliza con una breve conclusión sobre el aprovechamiento, la experiencia y la sistematización de los contenidos del curso "Planificación y Diseño Curricular". (Ver anexo $\mathbf{N}^{\circ}$ 1)

Esta sección final, se recomienda analizarla con cuidado, sobre todo ante la gran cantidad de juicios personales presentes y que son el resultado directo de la experiencia de este servidor con la práctica; tanto en la labor docente de Estudios Sociales como en la administrativa para la educación secundaria.

Por eso, no deben ser tomadas como críticas destructivas, sino como parte del proceso de formación constante en el sano juicio profesional. La idea aquí no es entrar en conflicto, pues, el académico universitario no puede "desacreditar" la labor docente sin conocer de antemano la filosofía pedagógica que sustenta los pensamientos del ensayista y el ensayista no puede "desacreditar" al académico orgánico universitario por un principio oriental de respeto al maestro.

La idea o el propósito central de este artículo, es promover la discusión y la reflexión en torno a una de las fases de la planificación curricular: la planeación de unidades didácticas.

Dicha unidad está centrada en uno de los contenidos del programa de sétimo y en el campo de los Estudios Sociales, pues, en este nivel el suscrito ha 
desarrollado un amplio trabajo de investigación y docencia. Se selecciona el paradigma cognitivo, ya que, el Ministerio de Educación Pública, trata de destacarlo en sus programas curriculares actuales y es uno de los paradigmas que promueve también la Universidad Nacional para sustituir al conductismo.

Se busca así aportar en este aspecto, para mejorar la práctica docente dentro del proceso de enseñanza en la educación costarricense. 


\section{I \\ "El Papel del Planeamiento Didáctico \\ Dentro del Paradigma Cognoscitivo en \\ el Futuro Diseño Curricular"}

En un país como Costa Rica, la educación es vista como una herramienta de legitimación del sistema imperante que dicta desde los escritorios burocráticos, el qué enseñar, el cómo enseñar y cuándo enseñar apegados a un currículo oficial, donde la teoría conductista sobresale como el "elefante blanco o la panacea" que brinda la seguridad necesaria al sistema, en la consecución de los contenidos propios de la cultura sistematizada.

Sin embargo, en los últimos años del siglo que acaba de expirar, el Ministerio de Educación Pública, promueve toda una pedagogía de cambio centrada en tres enfoques básicos: el constructivismo, el racionalismo y el humanismo. Actualmente, se realizan esfuerzos importantes para incorporar definitivamente estos enfoques en los salones de clase, de hecho, el constructivismo que es una rama del paradigma cognoscitivo, busca abrirse paso dentro del conductismo como pedagogía alternativa que puede llegar a minimizar las críticas (poco delicadas) sobre el qué enseñar, el cómo enseñar y el cuándo enseñar en el proceso de enseñanza.

Es así como el paradigma cognitivo, surge como una alternativa de aprendizaje cognoscitivo que desde el punto de vista de significancia, puede concebirse como:

"El aprendizaje significativo que la persona realiza (idiosincrático) es compartido en situaciones sociales, lo cual posibilita la construcción del conocimiento para una mejor apropiación de la realidad. Una visión del mundo que supone la construcción social del conocimiento por individuos que comparten 
significados en un espacio y tiempo específicos". (Flores y Reyes, 1996, p.13-15)

Aquí sobresalen una gran cantidad de exponentes, desde Piaget hasta Ausubel, Novack, Vigotsky, Bruner y Claxton, el aprendizaje significativo es un modelo central dentro del paradigma cognoscitivo que como tal, tiene sus raíces históricas en el siglo XVIII en Europa, en contraposición al positivismo.

Para este paradigma entonces, el estudiante posee cierto cuerpo de conocimientos, los cuales determinan sus actitudes y acciones y se le debe animar a descubrir hechos de toda índole, por lo tanto el(la) docente será un promotor, un facilitador del desarrollo cognitivo de los(as) educandos.

No obstante, esto no es posible sin la existencia de un planeamiento didáctico que guíe u oriente la labor docente en el futuro diseño curricular.

La planificación curricular, es un concepto muy amplio y complejo, pues, se puede desarrollar desde el nivel nacional, regional, local hasta de aula. La planeación didáctica es (desde el punto de vista estructural) una fase o un momento de la planificación curricular, implica:

"Una actividad dinámica y cambiante. Consiste en tomar del programa de estudios los contenidos curriculares; distribuirlos y organizarlos de una manera más o menos lógica en planes anuales, trimestrales y de clase". (Arce y Quesada, 1991, p.14)

El planeamiento didáctico, es un recurso que utiliza el educador, una ayuda para planificar, organizar y desarrollar el trabajo (actividades, ejes problema, metodología, evaluación, contenidos) con el objeto de aumentar su eficiencia.

La meticulosidad en su elaboración permitirá emplear mejor el tiempo, para la consecución de los ejes problema con mayor seguridad y en un proceso de retroalimentación continua. 
El planeamiento didáctico, dentro del modelo cognitivo no sólo debe considerar el esquema mental del estudiante dentro de su realidad inmediata, sino que debe relacionar los contenidos de cada tema y hacerlos atractivos y significativos al estudiante según necesidades y aspiraciones particulares.

Los Estudios Sociales, al ser una disciplina multiauxiliar, es decir, apoyada en varias ciencias sociales y naturales, se presta para analizar el fenómeno de los "desastres naturales" en sus dos vertientes: física (relacionado con la geografía, la geología, la meteorología) y humano (sociología, demografía, psicología, historia). De este modo, se le ofrece al estudiante dos puntos de vista distintos que pueden simplificarse en los diferentes niveles del planeamiento didáctico que, para efectos de esta propuesta recae en el plan de unidad.

El plan de unidad (Quincenal - dos semanas) se fundamenta en una orientación psicológica que privilegia la globalización sobre la fragmentación, elementos que en la práctica educativa se traduce en la organización del programa de un curso en sectores significantes, definidas como unidades que contienen un eje temático o problemas varios de un aspecto.

Al respecto expresa Nérice (citado por Arce y Quesada), sobre el concepto de unidades como:

"Conjuntos de hechos, datos o comportamientos interrelacionados y formando un conjunto que se aprende más fácilmente debido a su comprensibilidad y significación. De este modo, la unidad evita que el alumno aprenda datos aislados que únicamente con mucho esfuerzo pueden ser asimilados". (Arce y Quesada, 1991, p.19)

Si se entiende al planeamiento curricular como un conjunto de procesos que involucran la previsión, realización y evaluación, el plan de unidad es la 
expresión más simplificada del planeamiento curricular y la planeación curricular una fase central de la planificación curricular.

Como puede desprenderse de todo el análisis realizado hasta este punto, el plan de unidad tiene como propósito ordenar, seleccionar y adecuar los contenidos, conceptos y problemas a la realidad más inmediata presente en el salón de clases: el estudiante.

Luego de este panorama conceptual, es necesario presentar la estructura del planeamiento didáctico, bajo el modelo de plan de unidad para el tema "desastres naturales" en el área de Estudios Sociales, $7^{\circ}$ año.

\section{II \\ "Modelo de un Plan de Unidad Para el Tema de Estudios Sociales: Desastres Naturales"}

La unidad que se desarrolla aquí, es viable tanto para los colegios públicos como para los privados. La unidad puede ser remodificada según el contexto social a la que está dirigida, a la naturaleza de los contenidos, el tipo de población estudiantil, el libro de texto seleccionado, los materiales existentes en la institución, los recursos del docente y otros rubros.

La unidad está organizada (aspectos que se sugieren básicos) en tres partes fundamentales:

(1) Una estructura inicial (encabezado)

(2) El desarrollo (cuerpo de la unidad)

(3) La descripción final (descripción y explicación de cada elemento contenido en el desarrollo). 
1. Encabezado:

\section{Modelo de un Plan de Unidad}

Centro Educativo: "Colitas" Nivel: $7^{\circ}$ año Asignatura: Estudios Sociales

Profesor: Lic. AMR Tema abarcado: Desastres Naturales Año: 2001 Total estudiantes: $\_$. Período: Quincenal . Total lecciones: $8 \mathrm{~L}$. 
3. Descripción final: El modelo de unidad anterior, está estructurado para ser aplicado en cualquier colegio de educación pública o privada. No obstante, es necesario profundizar en cada uno de sus elementos para que el lector detecte la secuencia lógica (de acuerdo con el paradigma cognitivo) y de articulación que es uno de los requisitos principales de la planificación y el diseño curricular.

Hablemos un poco de los 7 elementos contenidos en los dos cuadros anteriores de la unidad sobre el tema de "desastres naturales" (en orden de izquierda a derecha).

\section{EJES PROBLEMA:}

El tema de los "desastres naturales", es muy amplio y su conocimiento implica la selección intencionada de ejes que ubiquen o focalicen la temática, bajo situaciones problema en el desarrollo de la discusión y la reflexión.

Las preguntas intencionadas promueven la activación de la mente de los(as) estudiantes, hace que lo cognitivo se explote bajo la lluvia de ideas (relación ejes-problema y procedimientos) en el intercambio de la información previa con la información futura (libro de texto y el profesor-recurso y materiales). Inclusive las preguntas generadoras pueden ser futuros proyectos que los(as) estudiantes pueden retomar para los planes de prevención.

\section{CONTENIDOS PROGRAMÁTICOS:}

Aquí están desglosados de forma intencional (lo más significativo), es decir, en 4 sectores de significancia, cada uno con una serie de conceptos que engloban toda la problemática. Puede notarse que no son contenidos recargados y aparte de tres sectores de contenidos (Tipos de desastres naturales, provocados y de medidas de prevención y aplicación), se considera a las ideas previas como un 
sector de conocimiento de significancia que realza la parte cognoscitiva del estudiante.

Los contenidos, por sí solos limitan mucho la labor docente si no se desarrollan de forma atractiva hacia los educandos. En este caso y para eliminar o minimizar este problema, los contenidos son explicados bajo una serie de imágenes (íconos) que ilustran cada uno de los fenómenos naturales y provocados, con un espacio abajo para que el estudiante realice la interpretación de esa imagen visual.

El siguiente ejemplo ayuda a clarificar esta secuencia e integración:
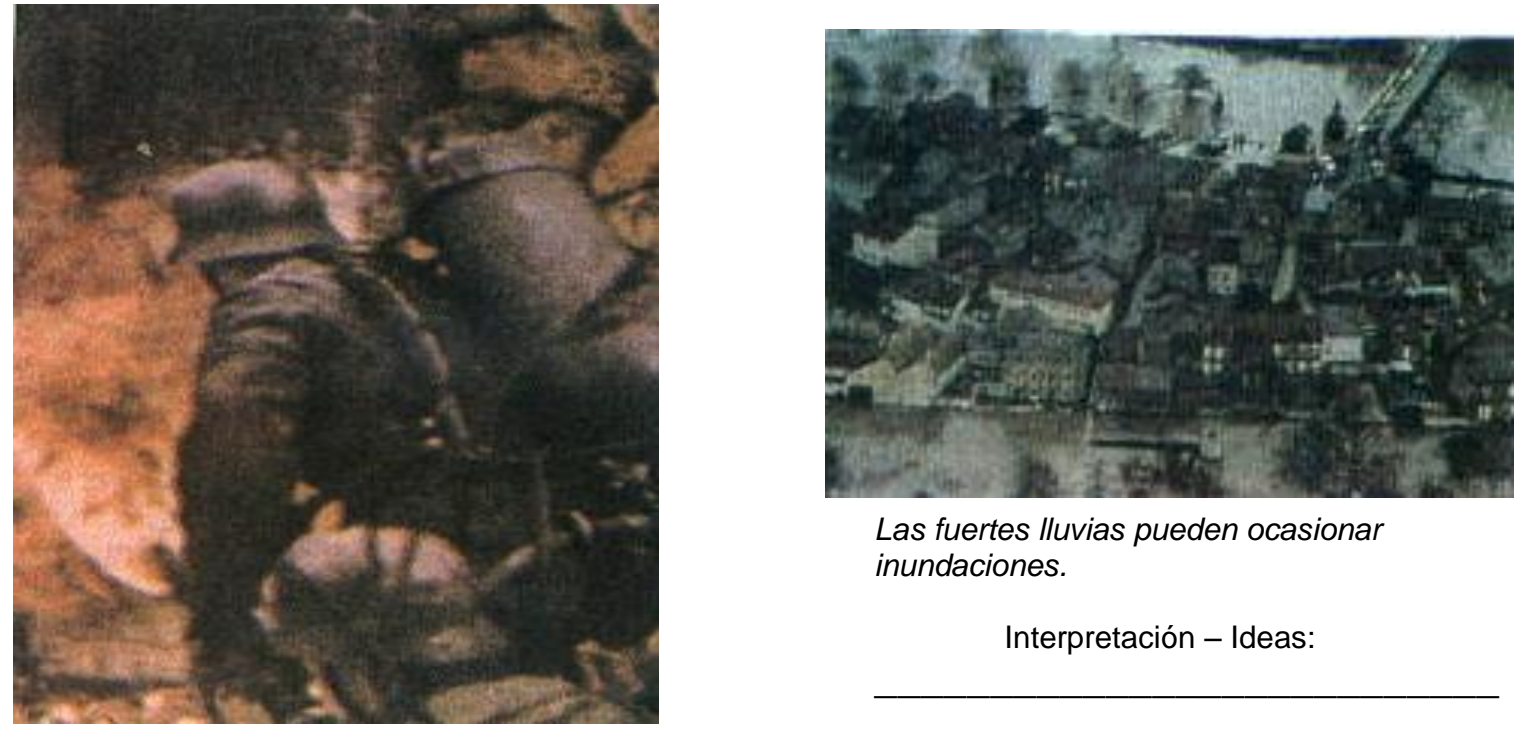

Las fuertes lluvias pueden ocasionar inundaciones.

$$
\text { Interpretación - Ideas: }
$$

Las guerras son uno de los acontecimientos más ilógicos de la humanidad.

Interpretación - Ideas:
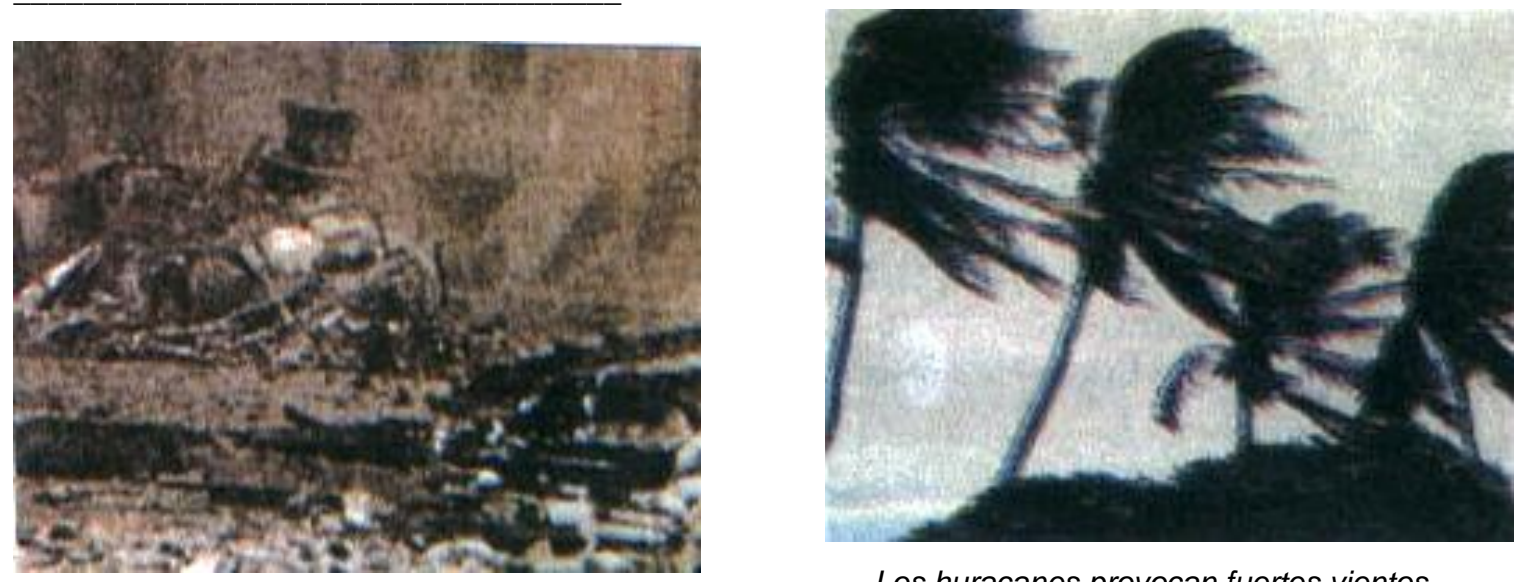

Los huracanes provocan fuertes vientos 


\section{RECURSOS:}

En cuanto al escogimiento y la aplicación de los recursos no hay nada dicho, pues, el panorama pedagógico ofrece la posibilidad de utilizar diferentes. Desde el mapa conceptual hasta la rejilla conceptual. Aquí se combinan diferentes recursos cognitivos, la lluvia de ideas que sirve como diagnóstico previo al conocimiento inicial del estudiante. La guía puede ser conceptos o preguntas generadoras que se desprenden de los EJES PROBLEMÁTICOS.

También se desarrolla la clase expositiva ilustrativa que es la combinación de texto con imágenes o íconos para estimular lo visual en el estudiante y el desarrollo del Mapa Semántico que es un recurso que ayuda no sólo a ordenar la información sino a sintetizarla y que además se puede convertir en un material de apoyo como mapa de referencia bibliográfica.

El siguiente ejemplo, ayuda a visualizar cómo un "mapa semántico" (Méndez, 1995, p.34) ordena y sintetiza los contenidos en el tema "desastres naturales y provocados": 


\section{MAPA SEMÁNTICO DE 4 EJES}

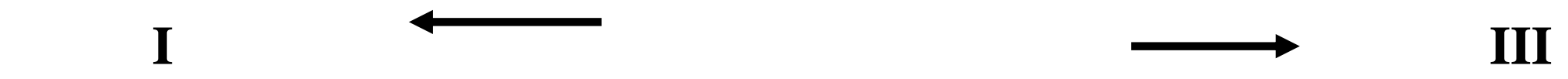

\begin{tabular}{|l|l}
\hline IDEAS & Información previa \\
\cline { 2 - 2 } PREVIAS &
\end{tabular}

- Ideas de los estudiantes.

- Conceptos sobre la temática. desglosar.

- Preguntas generadoras. visuales.
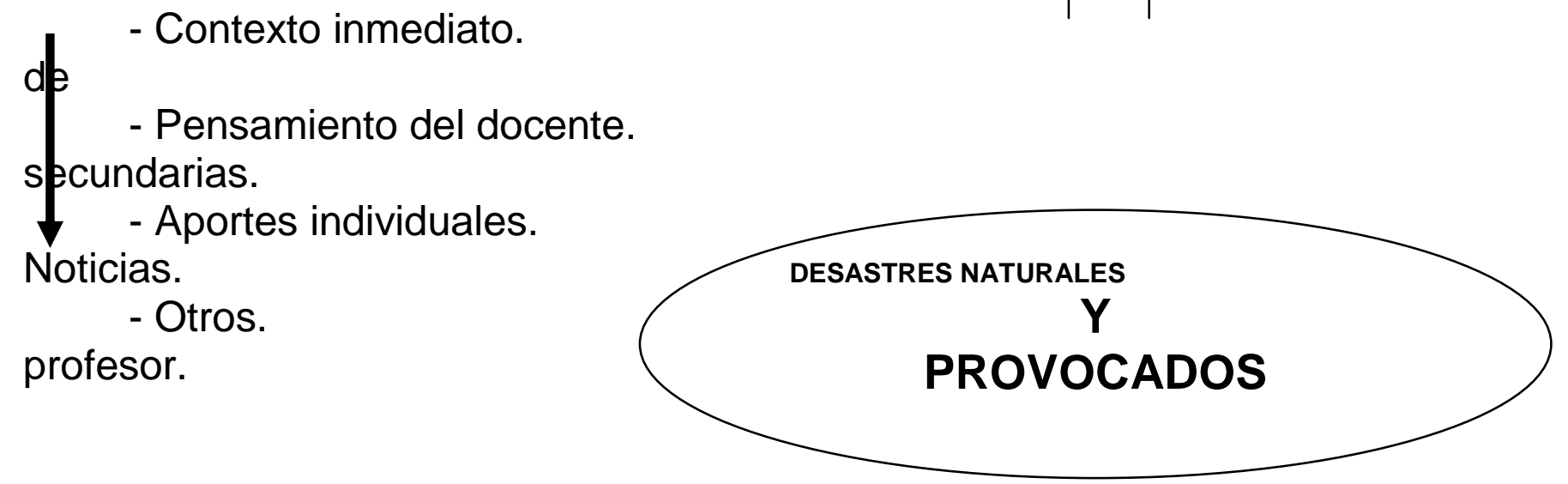

- $\quad$ Reportajes-

- Exposición del

- Aporte grupal.

II

\begin{tabular}{|l|l|}
\hline DESASTRES \\
NATURALES
\end{tabular}

IV

\begin{tabular}{|l|l|}
\hline Inf. de Conclusión & MEDIDAS \\
PREVENCIÓN Y Y \\
APLICACIÓN
\end{tabular}


- Libro de texto.

Grupales de los

- Contenidos a desglosar.

prevención.

- Imágenes visuales.

Mapa Semántico

- Otra información de diferentes fuentes.

profesor bajo

- Exposición del o la profesora.

evaluativa.
- Exposiciones

planes de

- Síntesis del

para incorporar.

- Cierre del

actividad

- Bibliografía adicional a la del libro de texto. 
Todos estos recursos cognitivos, deben apoyarse en una serie de materiales que aporta el contexto o son elaborados por el mismo educador durante su labor extra-curricular.

\section{MATERIALES (apéndice del anterior elemento $\mathrm{N}^{\circ} 3$ ):}

Como son partes físicas, es decir, visibles y palpables, el (la) docente puede utilizar otros que no sean los sugeridos aquí (Papel periódico, pilot, libro de texto, recortes-ilustraciones y material fotocopiado) por ejemplo, materiales de desecho, un video del tema y otros. Éstos deben, sin embargo, ajustarse a las necesidades de cada quien y según el presupuesto disponible. Libro de texto utilizado en esta unidad.

\section{PROCEDIMIENTOS:}

La secuencia y la articulación son primordiales en este elemento. En cuanto a la secuencia, cada actividad metodológica presentada está organizada en orden de aparición, en otras palabras, una liga a la otra bajo un puente cognitivo que evita la fragmentación. Las ideas previas en la actividad de la "lluvia de ideas", por ejemplo, debe llevar al estudiante a relacionar su información previa (esquema mental) con la nueva información (desequilibrio cognitivo), para luego con la lectura de texto y las imágenes más la explicación del profesor (volver al equilibrio cognitivo), pueda asimilar e interiorizar los conceptos para finalmente, bajo el proyecto del plan de prevención (apropiación cognitiva) logre construir conocimiento que sea significativo a su progreso y esto lo verifica por medio de la evaluación en sus tres etapas (diagnóstica, procesal y comprobatoria final). Esto le ayuda a autoevaluarse en cuanto a sus logros y retrocesos durante toda la experiencia de aprendizaje. La articulación se logra, cuando el(la) docente involucra todos los elementos en interrelaciones constantes, es decir, involucra la evaluación en las tres fases de las actividades, involucra los ejes en los contenidos, los valores y actitudes en la evaluación y el aprovechamiento de los recursos y materiales con los contenidos y el tiempo. 


\title{
ACTITUDES Y VALORES:
}

Aquí no se resalta el contenido, sino la actitud del estudiante frente al fenómeno en sí. Las actitudes y los valores son valiosos en la medida en que el estudiante logre sensibilizarse e incorporarlos a su esquema de valor. Que sienta compasión por el dolor ajeno, por la necesidad urgente de organizar planes de acción que ayuden, al menos en caso de un desastre, a mitigar los efectos sociales y humanos que ocasiona un fenómeno de estos.

\section{EVALUACIÓN:}

La evaluación es uno de los elementos más importantes dentro del proceso de enseñanza. Hay que eliminar la mentalidad de algunos(as) docentes que expresan (según criterios que escucho en mi práctica docente) que la evaluación es un "adorno que sólo se aplica al final y está dominada por la calificación numérica". En parte tienen razón, empero, la evaluación cognitiva es más que una nota, según el Ministerio de Educación Pública, la evaluación:

\begin{abstract}
"es un proceso que se lleva a cabo bajo tres funciones: diagnóstica, formativa y sumativa. La función diagnóstica permite caracterizar un programa 0 proceso y determinar su estado actual; la función formativa permite la toma de decisiones para ajustar áreas problemáticas, del programa o del proceso. La función sumativa permite valorar el producto final de un programa o proceso". (M.E.P., 1995, p.3)
\end{abstract}

Es importante destacar que la evaluación cognitiva considera todas las etapas del proceso de aprendizaje, desde la evaluación diagnóstica (Fase de inicio) donde el docente analiza las expectativas, metas, aspiraciones y limitaciones de los(as) estudiantes con respecto al tema básico a desarrollar; la evaluación formativa o procesal (de desarrollo) donde el docente conoce las deficiencias, los puntos fuertes de los(as) estudiantes y su relación con el contenido hasta la evaluación sumativa (que es la que provoca los problemas en los educadores) que no es más que la comprobatoria final bajo una calificación 
numeral, todas son abordadas en este modelo de unidad y pueden integrarse en un solo instrumento de evaluación.

El instrumento de evaluación es básicamente una herramienta, una ayuda que utiliza el(la) docente para calificar cuantitativamente y cualitativamente los progresos y limitaciones del estudiante en todo el proceso. Dicho "instrumento de evaluación” (M.E.P., 1996, p.19) debe presentar un encabezado central, una estructura (aspectos, variables o rubros a calificar más el criterio de valoración), un apéndice (criterio cuantitativo de valoración, que puede ser subjetivo, el $\mathrm{N}^{\circ}$ de lecciones evaluadas) y un espacio para observaciones (anotaciones adicionales del docente hacia el estudiante o la actividad evaluada).

Se presenta a continuación un ejemplo de un instrumento para evaluar cognitivamente todo el plan de unidad, no obstante se aclara que es parcial y sólo incluye algunos aspectos de las tres evaluaciones: Diagnóstica, Procesal y Comprobatoria.

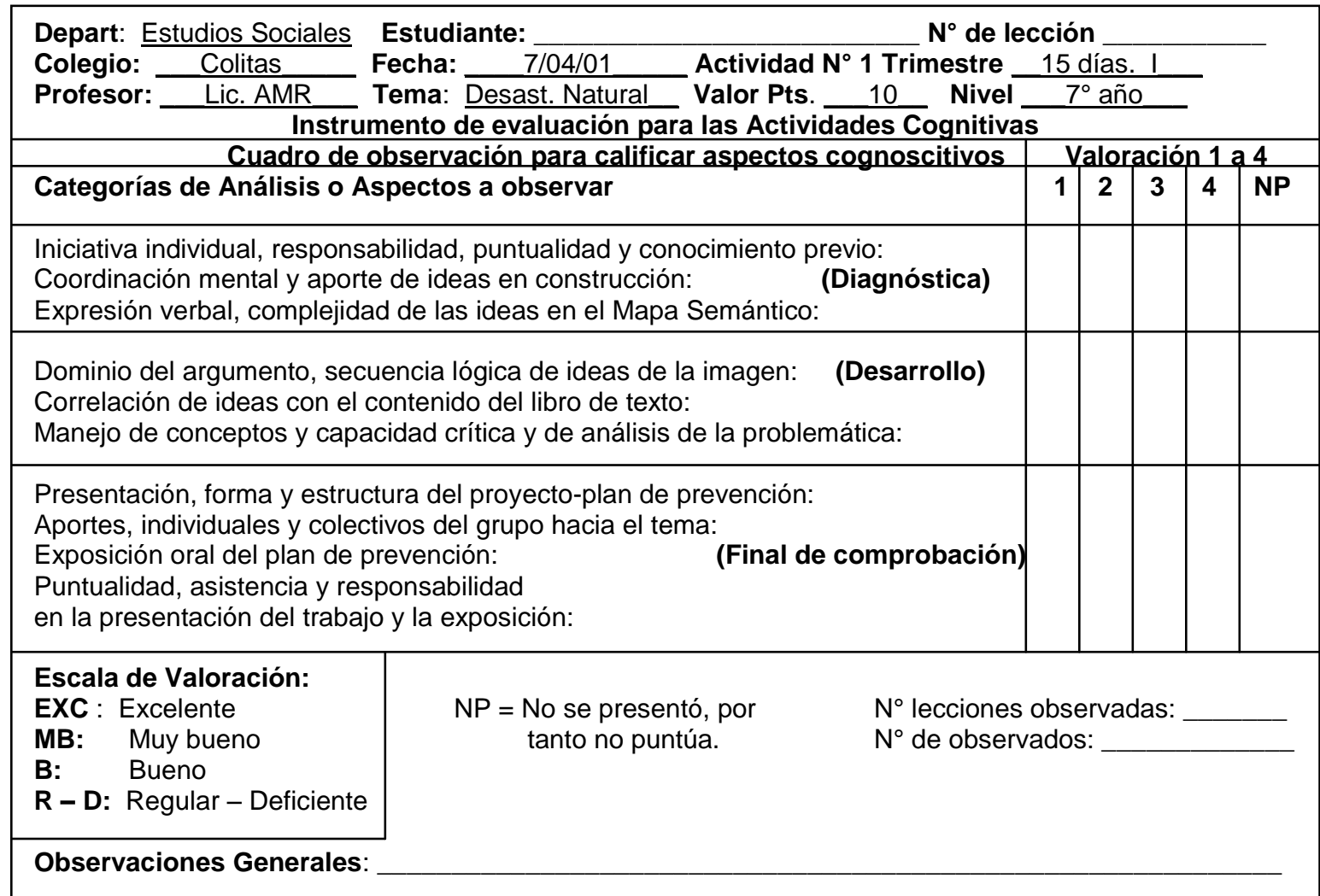




\section{TIEMPO PROBABLE:}

El tiempo probable no debe ser considerado rígidamente, en otros términos, como el contenido está seleccionado intencionalmente, las dos semanas (con un total de 8 lecciones) son viables para desarrollar la unidad en cualquier colegio. El docente debe organizar el tiempo y aplicarlo según la cantidad de estudiantes, según las tareas a desarrollar y las actividades totales de todo su planeamiento (valga el pleonasmo) para evitar choques con el otro plan futuro.

\section{III \\ "Recomendaciones, Ventajas y Limitaciones del Modelo de Plan de Unidad"}

Se esbozan a continuación una serie de recomendaciones, ventajas y limitaciones del modelo elaborado anteriormente.

\section{Recomendaciones:}

- La anterior propuesta de planeamiento didáctico, puede aplicarse tanto para colegios públicos como privados, no obstante, el docente puede realizar las adecuaciones que considere pertinentes siempre y cuando respete la fundamentación epistemológica de la teoría pedagógica seguida, es decir, se sugiere evitar las mezclas de paradigma en la parte operacional a no ser que sea estrictamente necesario.

- No debe ser tomada como una propuesta acabada, absoluta y estrictamente apegada a la teoría cognitiva, ya que, se recuerda la existencia de diferentes 
enfoques que abarcan desde el constructivista, el socioreconstruccionista hasta el heurístico.

- Se sugiere revisar alguna bibliografía actualizada sobre el paradigma cognitivo y sus diversas acepciones y vertientes (enfoques) antes de planificar, seleccionar, ejecutar y evaluar las futuras unidades en los diferentes tipos de planes (anual, de unidad, de lección, de administración). Lo mismo en el campo curricular, evaluativo y de metodología.

- Debe existir una reunión previa con todo el personal docente y de cada departamento para conocer la línea pedagógica a seguir según la filosofía institucional actual. Esto incluye conocer la política educativa actual del Ministerio de Educación Pública.

- Si es posible, el educador que no presente dominio de corrientes, enfoques, modelos o concepciones "de moda" debe asesorarse o solicitar ayuda a especialistas que estén actualizados en lo anterior.

\section{Ventajas posibles:}

* La propuesta le permite al educador valorar y diagnosticar su labor docente no sólo desde la teoría pedagógica, sino en la práctica educativa. Confrontación de sustentos teóricos con la práctica, para conocer las contradicciones y los aciertos en búsqueda de la adecuación pronta y la perfección profesional.

Puede ser utilizada para otros temas y en otras disciplinas como por ejemplo, la biología, la ciencia, la filosofía, la geografía y la meteorología entre otras. Es una alternativa interesante para abordar los contenidos, evita la rutina y al mismo tiempo lo presenta atractivo al estudiante con la posibilidad de enriquecer la lección gracias al aporte previo de sus estudiantes. 
* La propuesta es un arma que utiliza el docente para demostrar dominio de teorías pedagógicas. En otras palabras, la propuesta le brinda seguridad, autoestima y satisfacción interna, aparte de que esa meticulosidad en la "planificación-planeación-plan", le genera gratificación externa, dominio del grupo, control del tiempo y manejo adecuado de actividades.

\section{Limitaciones:}

- La libertad que el docente genera con este paradigma, sobre todo porque el estudiante es el eje central del aprendizaje, puede provocar un exceso que limita seriamente el tiempo disponible y las actividades pueden quedar "cortadas" o por la limitación del tiempo se precipitan (no se profundizan los contenidos).

- En grupos muy grandes, con una cantidad de estudiantes (más de 40 estudiantes), la actividad expositiva puede ser que no ofrezca resultados positivos y se cometa errores de apreciación y valoración subjetiva durante la evaluación en todas sus fases. Se califica a los que exponen con nota mayor y los que no con nota inferior.

\section{IV \\ CONCLUSIONES?}

Es necesario que los(as) educadores dejen de depender de los especialistas curriculares, para desarrollar sus propias estrategias de aprendizaje, ya que, una cosa es elaborar o construir planeamientos didácticos desde un escritorio burocrático y otra en la "escena" educativa. 
No comparto la opinión (de algunos compañeros) donde se expresa que la mayoría de los(as) docentes "están sujetos a un sistema curricular oficial y no se pueden hacer modificaciones, lo cual, provoca el estrangulamiento de la originalidad y la creatividad en su máxima expresión".

Si usted es un profesional que no se actualiza, no escucha sugerencias, es intransigente con otros colegas de su especialidad, no valoriza el aporte de la cultura cotidiana previa de los(as) estudiantes y no se autoevalúa en la labor docente, difícilmente puede cristalizar sus propios proyectos pedagógicos.

Si la labor docente está enmarcada dentro de una política curricular oficial, hay que salirse de ese esquema y realizar las adecuaciones o modificaciones bajo la construcción de una planificación y un diseño curricular serio dirigido hacia todos los elementos que articulen y secuencien una estructura. No se cuestiona aquí el tipo, modelo o teoría pedagógica a seguir, se puede ser un excelente conductista si los fundamentos teóricos son coherentes con la práctica; lo que puede discutirse aquí es la inconsistencia entre los sustentos epistemológicos (asumidos, impuestos o adoptados y dominados por el docente) de la teoría pedagógica y su aplicación práctica (operativa).

Por otro lado, el educador debe manejar no sólo una teoría sino un plan preconcebido de qué es lo que va a desarrollar en la práctica docente. El qué enseñar, el cómo enseñar y el cuándo enseñar (involucra la evaluación), están sujetos a una gran cantidad de elementos que muchas veces escapan a la planificación y el diseño curricular.

Los ejes problema, propósitos, objetivos (como se le quiera llamar) o metas; los contenidos (conceptos); las actividades (metodología, secuencia, procedimientos); los recursos y materiales (partes visibles); los valores (actitudesconductas); la evaluación (procesal, diagnóstica, sumativa, comprobatoria) y el tiempo (cantidad de minutos invertidos por actividad) deben estructurarse en 
plena coordinación para realizar las adecuaciones pertinentes según el contexto inmediato.

De todo el análisis, la experiencia adquirida y el bagaje propio realizado hasta ahora, quedan una gran cantidad de preguntas sin respuesta, no obstante, queda abierta la puerta para ahondar en algunas de ellas:

Si el currículo busca la integridad en todos los elementos bajo una estructura articulada, ¿cuál es el modelo o los modelos curriculares más idóneos, para desarrollar, si todos los contextos particulares son diferentes?

Uno de los objetivos centrales del currículo es transformar la enseñanza llevando los sustentos teóricos a la práctica, ¿qué estrategias de enseñanza pueden ser operacionalizadas desde el punto de vista de la Administración Educativa que satisfaga la visión de las políticas curriculares actuales?

Si los(as) profesores de algunas universidades públicas (privadas no critico, pues, nunca he recibido en ellas), promueven el cambio desde la perspectiva curricular superior, ¿por qué algunos académicos continúan reproduciendo modelos curriculares tradicionales en algunos de sus elementos, por ejemplo: la evaluación?

¿Se actualizan los(as) docentes en servicio en materia de planificación y diseño curricular. Qué aportes realiza el Ministerio de Educación Pública con respecto a esta problemática?

¿Es posible un currículo integrado o mosaico en nuestro sistema educativo desde el punto de vista operacional para la labor docente? 


\section{BIBLIOGRAFÍA}

\section{Libros y Revistas:}

- Arce Ana y Quesada Marta. 1991. Compendio de currículo, II Parte. Planeamiento didáctico y diseño curricular. Edit. UNA. Heredia, Costa Rica.

- Ausubel, D. 1989. Psicología educativa. Un punto de vista cognoscitivo. Edit. Trillas, D.F, México.

- Bolaños B. y Molina B. 1990. Introducción al currículo. Edit. UNA. Heredia, Costa Rica.

- Flores E. y Reyes A. 1996. Estrategias de evaluación. Edit. UNA. Heredia, Costa Rica.

- González, Luis. SF. Teorías educativas, concepciones curriculares y corrientes pedagógicas. Revista Universitaria (CINDA). Chile.

- Hernández, Orozco. 1990. Planificación y programación. Edit. EUNED. San José, Costa Rica.

- Méndez, Zayra. 1995. Aprendizaje y cognición. Edit. EUNED. San José, Costa Rica.

- Ministerio de Educación Pública. 1995. Marco de referencia técnico y normas en materia de evaluación en los aprendizajes y del desarrollo socio-afectivo y ético de los estudiantes. Edit. MEP. San José, Costa Rica.

1996. Guía para aplicar el marco de referencia y las normas reguladoras del proceso educativo en la educación formal. Edit. MEP. San José, Costa Rica.-

- Newan, D. y Cole M. 1997. La zona de construcción del conocimiento. Trabajando por un cambio cognoscitivo en educación. Madrid, España.

- Novack, Joseph. 1988. Aprendiendo a Aprender. Edit. Martínez. Barcelona, España.

- Núñez, Soto y Campos Mary. 1998. El uso y aprovechamiento de los materiales didácticos en los Estudios Sociales: un balance sobre la relación teórica y práctica pedagógica. Revista Perspectivas № 1. Edit. UNA. Heredia, Costa Rica. 
- Pichardo, Muñiz A. 1984. Planificación y programación social. Edit. EUCR. San José, Costa Rica.

\section{Tesis Consultadas:}

- Alfaro A. y Eliette C. 1996. Una secuencia de aprendizaje significativo respaldada en el uso de la imagen para el desarrollo del tema: La guerra en la sociedad. Heredia, Costa Rica.

- Carrillo, R. y Juan C. 1997. Propuesta curricular para la enseñanza de los Estudios Sociales dentro del sistema penitenciario nacional. Heredia, Costa Rica. 
$-25-$

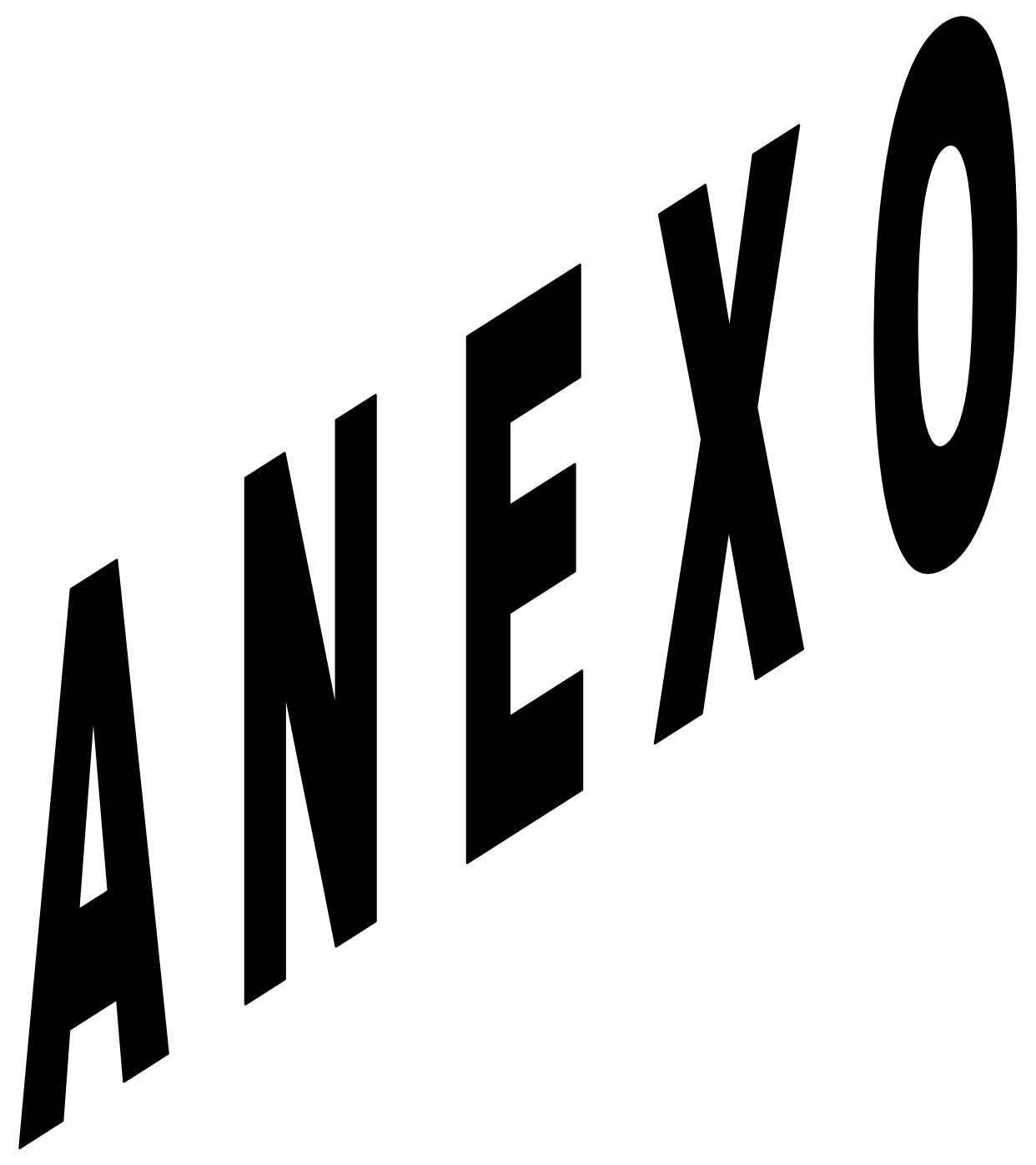




\section{Anexo 1.}

\begin{tabular}{|c|c|c|c|c|c|c|}
\hline 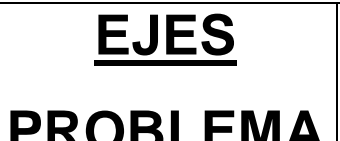 & $\begin{array}{c}\text { CONTENIDOS } \\
\text { PROGRAMÁTICOS }\end{array}$ & RECURSOS & PROCEDIMIENTOS & $\begin{array}{c}\text { ACTITUDES } \\
Y \\
\text { VALORES }\end{array}$ & EVALUACIÓN & $\begin{array}{c}\text { TIEMPO } \\
\text { PROBABLE }\end{array}$ \\
\hline $\begin{array}{l}\text { ¿Es necesario recibir } \\
\text { una } \\
\text { adecuada y desarrollar } \\
\text { una actitud preventiva } \\
\text { ante los desastres? } \\
\text { En caso de un } \\
\text { desastre natural, } \\
\text { ¿sabes dónde acudir y } \\
\text { qué medidas tomar? } \\
\text { ¿Existe en su barrio } \\
\text { un comité organizado } \\
\text { en caso de un } \\
\text { desastre natural o } \\
\text { provocado? }\end{array}$ & $\begin{array}{l}\text { "Desastres } \\
\text { Naturales y } \\
\text { provocados por el } \\
\text { hombre" }\end{array}$ & 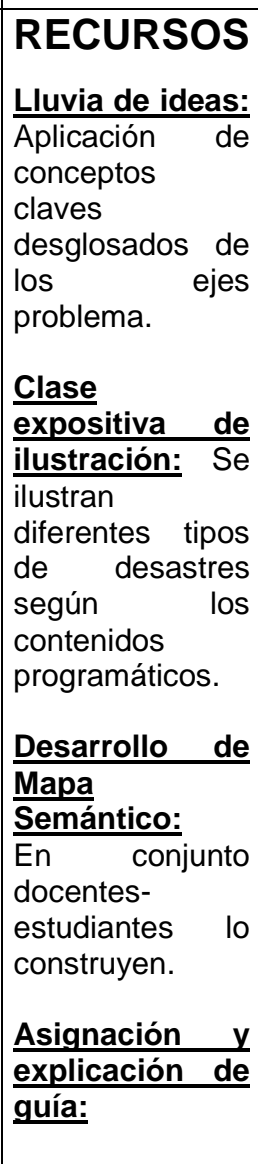 & 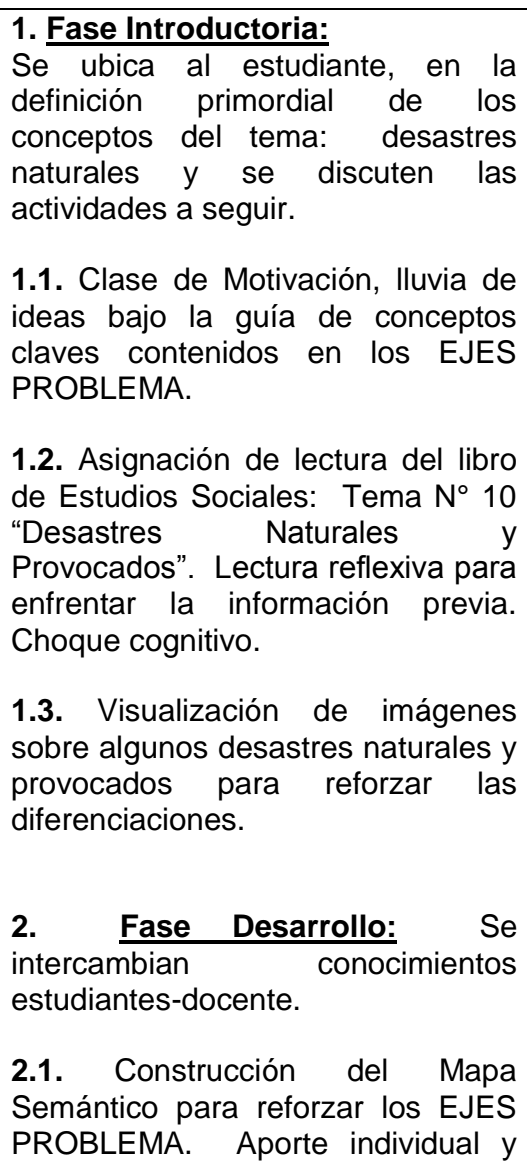 & $\begin{array}{|lr|}\text { - Valoro } & \text { la } \\
\text { importancia } & \text { de } \\
\text { recibir } & \text { una } \\
\text { educación } & \\
\text { adecuada, } & \text { para } \\
\text { prevenir } & \text { y } \\
\text { actuar en } & \text { caso } \\
\text { de un desastre } \\
\text { natural } & \text { o } \\
\text { provocado. } & \\
\end{array}$ & $\begin{array}{l}\text { La evaluación se } \\
\text { desarrolla en tres fases } \\
\text { centrales, a saber: } \\
\text { (1) Diagnóstica: } \\
\text { Se rescatan las ideas } \\
\text { previas del estudiante con } \\
\text { la nueva información } \\
\text { sobre la importancia de } \\
\text { los fenómenos naturales y } \\
\text { provocados. } \\
\text { Trabajo individual } \\
\text { cotidiano. \% } \\
\text { (ver instrumento) } \\
\text { - Conocimiento previo. } \\
\text { - Definiciones. } \\
\text { - Contexto de } \\
\text { procedencia. } \\
\text { - Aportes y otros. } \\
\text { (2) la confrontación } \\
\text { Formativa-Procesal: Se } \\
\text { aplica la valoración de los } \\
\text { diferentes avances y } \\
\text { retrocesos del estudiante, } \\
\text { en la cognitivo) } \\
\text { (desequilibrio no información } \\
\text { de la nueva } \\
\text { con su esquema mental. }\end{array}$ & $\begin{array}{l}\text { Aproximadamente } \\
\text { son } 2 \text { semanas } \\
\text { completas. } \\
\text { Un total de } 15 \\
\text { días, } \\
\text { 4 lecciones } \\
\text { (1 semana) } \\
\text { más } 4 \text { lecciones } \\
\text { (2 semana), } \\
\text { distribuidas de la } \\
\text { forma siguiente: } \\
\text { ISEMANA } \\
\text { 1. lección } \longrightarrow \\
\text { - Motivación } \\
\text { grupal, actividad } \\
\text { de lluvia de ideas. } \\
\text { 1. lección } \longrightarrow \\
\text { lectura en la } \\
\text { clase. }\end{array}$ \\
\hline
\end{tabular}




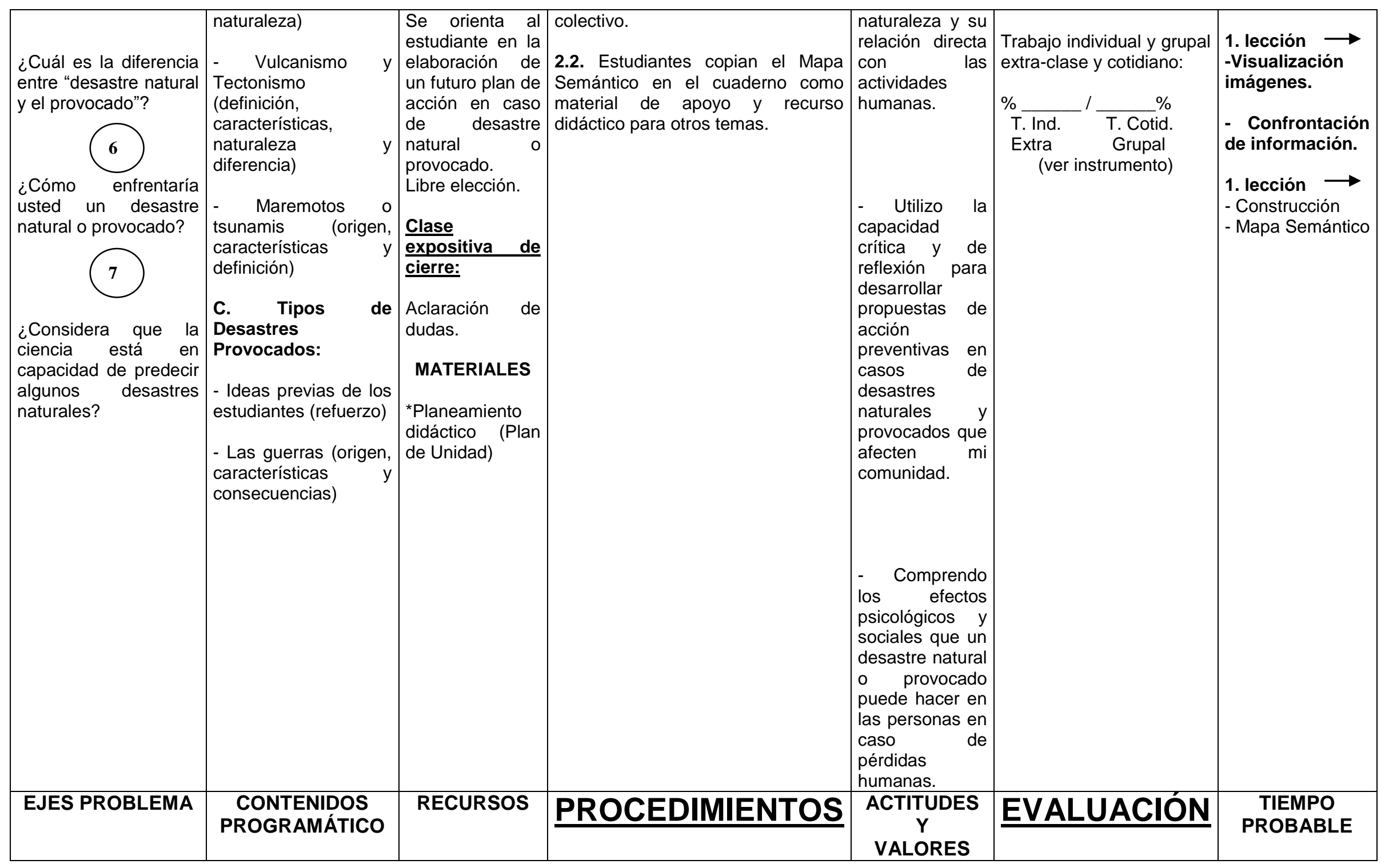




\begin{tabular}{|c|c|c|c|c|c|c|}
\hline $\begin{array}{l}\text { ¿Cómo afectaría su } \\
\text { vida cotidiana si fuera } \\
\text { parte de un desastre? }\end{array}$ & 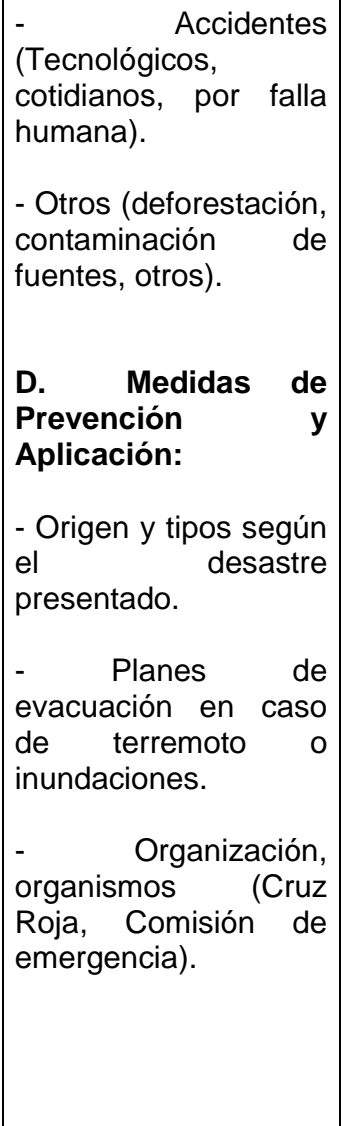 & $\begin{array}{l}\text { *Instrumento de } \\
\text { evaluación. } \\
\text { *Papel periódico, } \\
\text { pilot y cinta } \\
\text { adhesiva (Mapa } \\
\text { Semántico). } \\
\text { *Recortes de } \\
\text { libros de texto } \\
\text { para las } \\
\text { ilustraciones. } \\
\text { *Libro de } 7^{\circ} \text { año } \\
\text { de "Santillana". } \\
\text { *Material } \\
\text { fotocopiado } \\
\text { (guía para el } \\
\text { plan). } \\
\text { *Material-logro } \\
\text { del estudiante } \\
\text { (Trabajo grupal). }\end{array}$ & 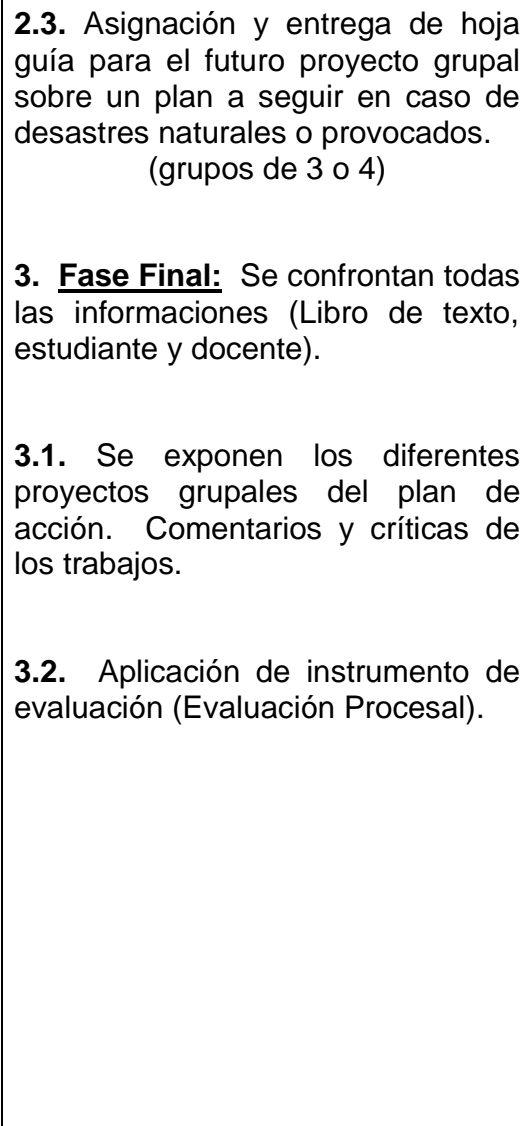 & 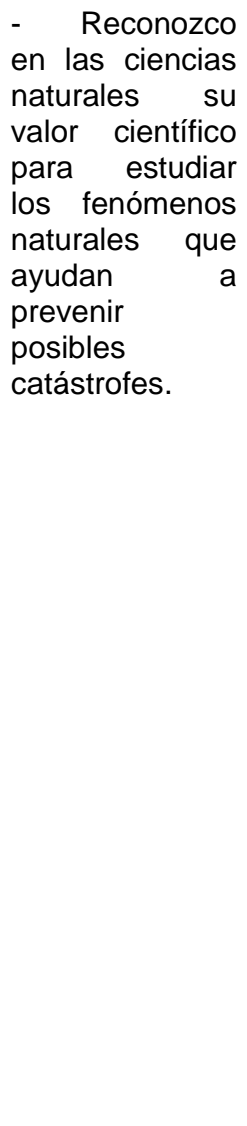 & 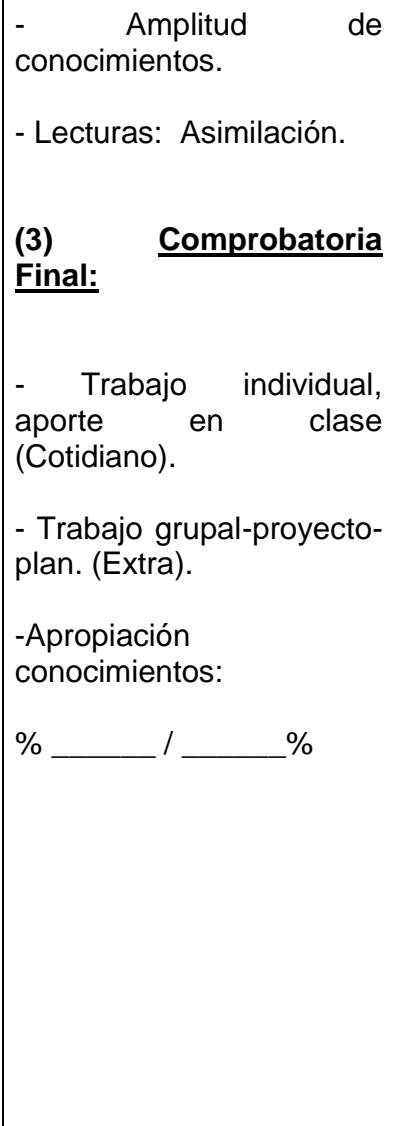 & $\begin{array}{l}\text { II SEMANA } \\
\text { 1. lección } \rightarrow \\
\text { - Conclusión del } \\
\text { Mapa y copia. } \\
\text { 1. lección } \rightarrow \\
\text { - Explicación de } \\
\text { guía sobre el } \\
\text { proyecto. } \\
\text { - Aclaración de } \\
\text { dudas y org. de } \\
\text { grupos. } \\
\text { 1. lección } \rightarrow \\
\text { - Exposición de } \\
\text { trabajos. } \\
\text { 1. lección } \rightarrow \\
\text { - Exposiciones y } \\
\text { cierre. } \\
\text { - Evaluación. }\end{array}$ \\
\hline
\end{tabular}


